\title{
BACCHANALIA NA REPÚBLICA ROMANA
}

\author{
MARIA LUIZA CORASSIN* \\ Faculdade de Filosofia, Letras e Ciências Humanas \\ Universidade de São Paulo
}

\begin{abstract}
RESUMO: Examinamos aqui uma fonte epigráfica, o senatus-consulto promulgado na época da repressão às Bacanais, no contexto político-social; este documento nos informa sobre as medidas tomadas em 186 a.C. pelo senado romano contra manifestações religiosas consideradas perigosas à ordem pública.
\end{abstract}

PALAVRAS-CHAVE: Bacanais; Dioniso; senado romano; história das religiões.

Um dos episódios mais conhecidos e comentados do mundo romano refere-se à repressão ocorrida no ano de 186 a.C. contra o culto de Baco, existindo uma relativamente ampla documentação textual: o relato de Tito Lívio, em XXXIX 8-19, e um documento epigráfico, o senatus consultum contendo medidas do Senado romano referentes ao caso. Estas são duas fontes independentes que se complementam.

Certamente menos divulgado que a passagem de Lívio, o texto epigráfico merece um exame que permita dele extrair elementos para sua melhor compreensão. A placa de bronze foi descoberta no século XVII, em 1640, perto de Tiriolo na Calábria ${ }^{1}$. Nesta placa está incisa a carta dos cônsules de Roma do ano de 186 a.C. dirigida aos magistrados da localidade denominada ager Teurano, dando ciência dos principais artigos de um senatus-consulto emitido com o objetivo de conter a difusão dos ritos báquicos na Itália. Trata-se, portanto, de um documento que registra a atividade legislativa do Estado romano em matéria religiosa.

Em suas origens o Senado era um órgão especificamente consultivo, não possuindo poder legislativo; podia apenas ratificar uma lei aprovada pelo povo. Posteriormente passou a ter a faculdade de discutir o projeto de lei do magistrado, antes de sua proposição ao povo; no entanto, nos últimos dois séculos da República a sua auctoritas viu-se muito aumentada: as instruções dadas pelo Senado aos 
magistrados sobre a administração da justiça tornam-se normativas, isto é, fonte de direito. O senado de regra interferia nos casos mais graves que alcançavam grande repercussão pública ou naqueles que tinham reflexos políticos. Utilizando seus poderes, podia solicitar de um magistrado, seja um cônsul ou um pretor, a atuação no processo que já era parte integrante do imperium deste magistrado.

Sendo um documento oficial, o senatus-consulto segue uma fórmula padrão. A primeira parte é a praescriptio, com os nomes dos magistrados que levaram a questão à deliberação dos senadores; a data e o local em que o Senado se reuniu; os nomes dos senadores que fizeram a redação. Em seguida, na relatio, há o texto da questão submetida à deliberação do Senado e por último a sententia, ou seja, a decisão dos senadores. Este documento sobre as Bacanais segue a regra: após indicar as várias ações proibidas, o senatus-consulto acrescenta a sanção prevista; é considerado delito passível de pena capital a violação das normas e das proibições nele estabelecidas: sei ques esent, quei arvorsum ead fecisent quam suprad scriptum est, eeis rem caputalem faciendam censuere.

O culto em si não foi proibido, sendo permitido continuar a sua prática por grupos de no máximo cinco pessoas, desde que autorizado pelo pretor urbano. Basicamente foi proibida a associação de indivíduos com o objetivo de celebrar em conjunto o culto dionisíaco. Lívio, ao narrar a repressão dos ritos báquicos na Itália em 186 a.C., alude às medidas tomadas pelas autoridades e menciona este senatus-consulto de Bacchanalibus que parafraseia em parte (Liv. XXXIX 18, 8-9).

Este texto é entendido no sentido de que o Senado não introduzia uma nova penalidade, mas considerava o caso envolvendo as Bacanais como coniuratio, estando esta já incluída entre os delitos capitais. De Martino ressalta que, neste caso, foi ampliada a antiga categoria de delitos contra o Estado; assim, novos determinados atos passavam a ser considerados crimen adversus rem publicam, reentrando como uma figura peculiar do crime de perduellio. Segundo Lívio (LIv. XXXIX 16, 12), o Senado determinou aos cônsules que procedessem extra ordinem (Liv. XXXIX 14,6; 16,12), o que poderia significar simplesmente que o Senado pedia que a quaestio fosse colocada fora dos casos normalmente previstos para serem tratados pelos magistrados (DE MARTINO, 1973, p. 204-205).

A epígrafe em sua brevidade é eloqüente para demonstrar a importância assumida pelo caso naquele momento, a ponto de atrair a atenção das mais altas esferas do poder:

Sc. De Bacchanalibus (CIL I ${ }^{2}$ 581; X, 104; ILS 18)

[Q.] Marcius L. f., S(p.) Postumius L. f. co(n)s(ules) senatum consoluerunt n(onis) Octob(ribus) apud aedem | Duelonai. 
Sc(ribundo) arf(uerunt) M. Claud(ius) M. f., L. Valeri(us) P. f., Q. Minuci(us) C. f.

De Bacanalibus quei foideratei | esent, ita exdeicendum censuere: 'Neiquis eorum [B] acanal habuise velet; sei ques | esent, quei sibei deicerent necesus ese Bacanal habere, eeis utei ad pr(aitorem) urbanum | Romam venirent, deque eeis rebus, ubei eorum v[e]r[b]a audita esent, utei senatus $\mid$ noster decerneret, dum ne minus senator $<\mathrm{i}>$ bus $\mathrm{C}$ adesent $<$ quom e $>$ a res cosoleretur.

Bacas vir nequis adiese velet ceivis Romanus neve nominus Latini neve socium | quisquam, nisei pr(aitorem) urbanum adiesent, isque de senatuos sententiad, dum ne $\mid$ minus senatoribus $C$ adesent quom ea res cosoleretur, iousisent. Censuere |

Sacerdos nequis vir eset; magister neque vir neque mulier quisquam eset; | neve pecuniam quisquam eorum comoine[m h]abuise velet; neve magistratum, | neve pro magistratu[d], neque virum [neque mul]ierem qui $<$ s $>$ quam fecise velet; | neve posthac inter sed conioura[se nev] comvovise neve conspondise | neve conpromesise velet, neve quisquam fidem inter sed dedise velet. | Sacra in [o] quoltod ne quisquam fecise velet; neve in poplicod neve in preivatod neve extrad urbem sacra quisquam fecise velet, nisei | $\operatorname{pr}($ aitorem) urbanum adieset, isque de senatuos sententiad, dum ne minus | senatoribus $\mathrm{C}$ adesent, quom ea res cosoleretur, iousisent. Censuere.

Homines plous $\mathrm{V}$ oinvorsei virei atque mulieres sacra ne quisquam | fecise velet, neve inter ibei virei plous duobus, mulieribus plous tribus | arfuise velent, nisei de pr(aitoris) urbani senatuosque sententiad, utei suprad | scriptum est.'

Haice utei in coventionid exdeicatis ne minus trinum | noundinum, senatuosque sententiam utei scientes esetis, - eorum | sententia ita fuit: 'sei ques esent, quei arvorsum ead fecisent quam suprad scriptum est, eeis rem caputalem faciendam censuere' - atque utei hoce in tabolam ahenam inceideretis, ita senatus aiquom censuit, | uteique eam figier ioubeatis, ubei facilumed gnoscier potisit; atque | utei ea Bacanalia, sei qua sunt, extrad quam sei quid ibei sacri est, | ita utei suprad scriptum est, in diebus X, quibus vobeis tabelai datai $\mid$ erunt faciatis utei dismota sient. - In agro Teurano.

Os cônsules Quinto Márcio, filho de Lúcio, e Espúrio Postúmio, filho de Lúcio, consultaram o Senado nas nonas de outubro², no templo de Belona. Estiveram presentes para a redação Marco Cláudio, 
filho de Marco, Lúcio Valério, filho de Públio e Quinto Minúcio, filho de Caio.

Sobre as Bacanais eles (os senadores) ordenaram que assim fosse notificado àqueles que se encontram na condição de aliados:

Que nenhum deles mantenha um local de culto a Baco; se houver alguém que alegue a necessidade de manter um local de culto báquico, deverá procurar o pretor urbano em Roma, e o nosso Senado, quando ouvir as suas alegações, decidirá sobre tal assunto, estando pelo menos cem senadores presentes quando se deliberar sobre o assunto.

Que nenhum homem, seja cidadão romano ou cidadão de direito latino, ou aliado, compareça a uma reunião de Bacas sem antes se dirigir ao pretor urbano e obter sua autorização, após sentença do Senado, estando pelo menos cem senadores presentes quando se deliberar sobre o assunto. Aprovado.

Que nenhum homem seja sacerdote (nas Bacanais); que nenhum homem ou mulher seja o dirigente; nem mantenha um fundo de dinheiro em comum; ninguém poderá nomear um homem ou uma mulher para mestre ou vice-mestre; nem doravante jurar entre si, fazer votos, promessas ou compromissos, e não empenhará a palavra com outros. Ninguém celebrará ritos sacros ocultamente; ninguém celebrará ritos sacros em público, nem privados, nem fora da cidade, sem antes dirigir-se ao pretor urbano e receber autorização após sentença do Senado, com pelo menos cem senadores presentes quando se deliberar sobre o assunto. Aprovado.

Pessoas em número maior de cinco ao todo, homens ou mulheres, não celebrarão ritos sacros, nem aí os homens estarão presentes em número maior do que dois e as mulheres do que três, exceto com sentença do pretor urbano e do Senado, nas condições acima estipuladas.

Estas normas serão notificadas em assembléias públicas por um período não inferior àquele de três dias de mercado ${ }^{3}$, e para que todos estejam cientes da sentença do Senado, a sentença foi: 'se alguém agir contrariamente ao que acima foi prescrito, que se faça um processo capital'; e o Senado decidiu que isto seja gravado em uma placa de bronze e que ordenem que seja afixada onde possa ser lida facilmente; e que dentro de dez dias após a entrega desta carta, providenciem para que todos os locais de culto báquico que possam existir sejam removidos, como foi ordenado acima, exceto se algum for consagrado. No ager Teuranus. 
Esta epígrafe é um testemunho da língua latina do século II a.C. Note-se o emprego de termos com um significado legal e jurídico que na tradução para o português perdem sua força e precisão: Bacanal, foederati, socii, magister e promagister. Mas a epigrafia não se limita à leitura e tradução do texto. Esta inscrição é enquadrada na categoria da epigrafia jurídica e os seus aspectos relacionados com a história político-social e religiosa receberão destaque. Embora desde o século XVIII tenha recebido um comentário ligando-a ao texto de Lívio, novas questões tem sido colocadas.

Em Roma, numa cidade sob o efeito das transformações provocadas pela segunda guerra púnica, ocorreu este escândalo que suscitou em 186 a.C. uma violenta repressão por parte das autoridades. O extenso relato deixado por Tito Lívio nos fornece o contexto em que se deu a proibição contida no senatus-consulto acima reproduzido. Com riqueza de pormenores, a sua narrativa chega a ter um aspecto novelesco, no qual as mulheres desempenham papel destacado na intriga com lances de folhetim. Para Mazzarino, Lívio caracterizou a arte histórica sobretudo como a arte da narrativa; este relato da repressão contém a marca de gênio de grande narrador de Lívio, o que significa, ao menos para os padrões antigos, de grande historiador (MAZZARINO, 1974, p. 38 s).

Deixando de lado o enredo romanesco, convém centralizar a atenção nas duas versões que Lívio dá sobre as origens do caso. Segundo ele, os cônsules Espúrio Postúmio Albino e Quinto Márcio Filipo foram encarregados de sufocar uma conspiração interna: Consulibus ambobus quaestio de clandestinis coniurationibus decreta est "a ambos cônsules foi ordenada a investigação de conspirações secretas" (LIV. XXXIX 8,3):

Um grego de ascendência obscura [...] estabelecera-se na Etrúria; era uma espécie de sacrificador e adivinho, mas não dos que predicam publicamente sua doutrina [...]; esse comportava-se como ministro de ritos secretos praticados à noite. A princípio iniciou certo número de pessoas em seu culto; depois começou a admitir indistintamente homens e mulheres, e para atrair maior número de prosélitos, associou os prazeres do vinho e da mesa às práticas puramente religiosas. A embriaguez, a obscuridade da noite, a mistura dos sexos e idades baniram para longe o pudor, abandonando-se a todos os gêneros de excessos. [...] Com gritos selvagens, alarido de tímpanos e címbalos, abafavam-se os gemidos dos que eram violentados ou as- 
sassinados. Essa asquerosa mácula passou como uma epidemia da Etrúria para Roma (Liv. XXXIX 8-9).

Aqui temos a primeira versão apresentada por Lívio sobre a introdução da "mácula" em Roma, relacionando-a com a Etrúria e com um graecus ignobilis desprovido da "admirável civilização helênica". Note-se a preocupação de Lívio em ressalvar a contribuição do povo grego para o romano nas artes que concorrem para o cultivo do corpo e da mente. Qualifica-o ainda de sacrificulus et vates, um sacrificador, ou seja, um sacerdote subalterno e como um adivinho.

Ao iniciar o relato da investigação levada a cabo pelo cônsul Postúmio, Lívio dá outra versão, aí incluindo a "novela" dos amantes Ebúcio, um jovem de boa família de nível eqüestre, de cuja fortuna o padrasto queria se apoderar, e uma rica e famosa cortesã, a liberta Híspala Fecênia. A mãe de Ebúcio, influenciada pelo marido, tentou desembaraçar-se do filho, ou colocá-lo sob seu controle, por intermédio da iniciação nos ritos báquicos. A liberta Fecênia, enamorada do jovem, alarmou-se quando este lhe revelou que iria se fazer iniciar nos mistérios de Baco. Quando escrava ela conhecera as abominações deste culto, o qual abandonara depois de liberta. Ao procurar a tia paterna, Ebúcio foi por ela aconselhada a avistar-se com o cônsul, denunciando o que ocorria. O cônsul Postúmio convocou Híspala, instando-a a revelar o que se passava no bosque sagrado de Estímula, onde aconteciam os mistérios noturnos das Bacanais. Aterrorizada com a presença do cônsul,

Híspala revelou-lhe a origem dos mistérios, informando que, a princípio, o santuário só se abria para mulheres, não se admitindo homens. Havia durante o ano três dias para a iniciação, feita à luz do sol. As matronas eram alternadamente investidas do sacerdócio. Pacula Ânia, da Campânia, durante seu sacerdócio mudou tudo: como a mandado dos deuses, começou a iniciar homens, e os primeiros foram seus dois filhos, Mínio e Herênio; transferiu a cerimônia do dia para a noite e estabeleceu que, ao invés de três, seriam cinco os dias do ano destinados à recepção de neófitos.

A partir deste momento "não havia excesso ou infâmia que não se realizasse, com os homens entregando-se mais aos desmandos entre si que na companhia das mulheres". Caso alguém resistisse, acabava imolado como vítima.

Como que ensandecidos, os homens profetizavam e se entregavam a fanáticas contorções; as mulheres trajadas de bacas e com os cabe- 
los soltos, desciam correndo ao Tibre empunhando tochas acesas, que mergulhavam na água e retiravam ainda incandescentes, pois continham uma mistura de cal e enxofre virgem. Diziam que os deuses arrebatavam os desgraçados, que na verdade eram amarrados a engenhocas e enfurnados em cavernas escuras. Escolhiam entre os que se recusavam a jurar participação nos crimes ou teimavam em não se deixar desonrar. Já eram tão numerosos que quase formavam um povo, incluíndo mesmo homens e mulheres de famílias nobres.

Outra condição que tinha sido imposta nos últimos dois anos era que "seriam iniciados apenas jovens de até vinte anos" (Liv. XXXIX 13). Nesta segunda versão, a Campânia era a área de proveniência do "mal", sendo a sacerdotisa Ânia a responsável pela transformação do rito já existente anteriormente.

Inteirados por Postúmio, os senadores mostraram-se alarmados pela segurança pública a qual poderia ser comprometida por uma conjuração tramada durante aquelas reuniões. $\mathrm{O}$ senado elogiou o cônsul por ter conduzido a investigação em sigilo e encarregou-o de prosseguir a devassa das bacanais e dos sacrifícios noturnos.

Seria publicado em Roma e em toda a Itália editos proibindo aos iniciados nos mistérios de Baco reunirem-se para celebrar aqueles ritos ou qualquer outro semelhante. Cumpria perseguir os que se juntassem ou jurassem atentar contra a honra e a vida dos cidadãos. Tal o decreto do senado.

Foram tomadas em seguida medidas de caráter policial a fim de deter os sacerdotes e manter a ordem na cidade (LIv. XXXIX 14,8-10).

O relato de Lívio parece alternar informações concretas sobre o episódio com trechos de ficção de romance. Interessantes são as colocações existentes no discurso atribuído ao cônsul Postúmio, pronunciado diante dos comícios, ou seja, diante da assembléia popular. Os pontos fundamentais que podemos extrair do longo trecho (Liv. XXXIX 15-16) referem-se a:

a) a condenação dirigida a cultos estrangeiros: "Coisa alguma contribui tanto para extraviar o homem quanto a superstição". "Quantas vezes, no tempo de nossos pais e avós, encarregaram-se os magistrados da tarefa de vetar cerimônias de culto estrangeiro; de excluir do fórum, do circo e da cidade sacerdotes e adivinhos; de apreender e queimar livros de profecias, de proscrever todos os ritos e 
sacrifícios que não fossem de acordo com o costume romano (more Romano)". "Acreditavam que nada tende a solapar a religião nacional como os sacrifícios praticados segundo um ritual estrangeiro" (Liv. XXXIX 16, 8-9);

b) o perigo representado por estas associações para o Estado: "Em relação ao seu número deixar-vos-ei aterrados se eu disser que já há milhares deles, a menos que acrescente quem são e de que espécie são. Em primeiro lugar, grande parte deles são mulheres - origem do mal -; depois há homens efeminados, corruptos ou corruptores, fanáticos, embrutecidos pelas noitadas, pelo vinho, pelo ruído dos instrumentos e pelos gritos noturnos. Até agora foi uma conspiração (coniuratio) sem força, mas que tende a se tornar temível porque diariamente arrebanha novos adeptos" (Liv. XXXIX 15, 8-10). "Seria menos sério se a sua depravação tivesse feito deles apenas efeminados - o que em grande parte era a infâmia deles- e se eles tivessem mantido afastadas suas mãos do crime e as mentes do delito: nunca teria havido tanto mal para o Estado nem tantas pessoas seriam afetadas de tantas formas" (LIv. XXXIX 16,1-2). Crescit et serpit cotidie malum. Iam majus est quam ut capere id privata fortuna possit: ad summam rem publicam spectat "Diariamente o mal cresce e se espalha. Já é demasiado grande para ser puramente um assunto privado: seu objetivo é o Estado" (Liv. XXXIX 16,3);

c) a preservação do mos maiorum: Ao pronunciar a invocação aos deuses com que abriu a assembléia, o cônsul a aproveitou como tema para iniciar o discurso dirigido aos cidadãos ali reunidos: "para nenhum outro discurso, cidadãos, seria tão adequada e necessária a solene prece pública que fizemos aos deuses: ela vos recorda quais deuses vossos antepassados estabeleceram para cultuar, venerar e invocar; não aqueles deuses que desejam impelir vossas mentes perturbadas por cultos depravados e estrangeiros, como incitadas pelas Fúrias, a todos os crimes e a todas as devassidões" (Liv. XXXIX 15,2-3);

d) o contraste entre as reuniões legalmente existentes e estes ajuntamentos noturnos: "Vossos antepassados não queriam que vocês se reunissem por acaso e sem motivo, a não ser quando o estandarte era colocado na cidadela e o exército era reunido em assembléia, ou quando os tribunos convocavam a assembléia da plebe ou algum dos magistrados os convocasse para uma reunião pública; Consideraram ainda que, onde quer que se reunisse uma multidão, estivesse aí presente uma autoridade legítima, encarregada de dirigi-la. De que espécie vocês acreditam ser, em primeiro lugar uma reunião noturna, e em segundo, com mulheres e homens misturados. Se vocês soubessem com que idade estes rapazes são iniciados, sentiriam não apenas piedade por eles mas também vergonha. Vocês acreditam, cidadãos, que no vosso exército se possa admitir jovens iniciados por este juramento?" (Liv. XXXIX 15,11-13). 
Aqui temos, portanto, o ponto de vista das autoridades sobre a perseguição a reuniões que representam o oposto de tudo o que é legalmente permitido: as assembléias do povo que se reuniam com finalidades eleitorais e legislativas eram diurnas, decorriam sob a presidência de um magistrado que as convocara, contavam com a presença exclusiva de cidadãos, os indivíduos de sexo masculino e maiores de idade. As mulheres, os estrangeiros, os menores de idade, os escravos, que se reuniam à noite, para celebrar divindades não pertencentes oficialmente ao culto público só podiam despertar desconfiança por parte do governo. Lívio coloca claramente este aspecto ao reproduzir o discurso atribuído ao cônsul. Os termos empregados remetem precisamente para o vocabulário concernente à praxe institucional: a reunião da comunidade cívica sob a presidência do magistrado legítimo e a articulação desta coletividade com as divindades, invocadas mediante o carmen. Lívio usa o variado vocabulário técnico-jurídico para indicar as assembléias: contio, cujo sentido tanto é o de discurso proferido numa reunião pública quanto a própria assembléia. Distingue os diferentes tipos de contiones nas quais era lícito aos cidadãos se reunirem: comitia centuriata, de caráter militar, que reunia os cidadãos em armas; concilium plebis convocado pelo tribuno da plebe. Além da precatio, Lívio menciona a sollennis comprecatio aos deuses, a prece pública pronunciada segundo os ritos pelo sacerdote ou pelo magistrado em voz alta e repetidas em voz baixa pelo povo.

Paillier ${ }^{4}$ considera que a iniciação báquica ameaçava absorver os rituais cívicos de iniciação dos jovens cidadãos romanos: dizia-se que as Bacanais transformavam em orgias homossexuais e em imitações de iniciação guerreira o que a tradição consagrava como acesso à dupla capacidade dos juvenes: a de gerarem uma posteridade para a família e para a cidade e a de defender ambas pelas armas no exército. Para Scheid (SCHEID, s/d, p. 490-491), o elemento mais alarmante para as autoridades nesta conjunção de marginais era aquele que justificava imediatamente a acusação de conjura: a agregação de rapazes muito jovens ao grupo báquico. A iniciação báquica pertencia às mães, naturais ou rituais, ou seja, a mulheres, que se substituíam ao papel que tradicionalmente cabia ao pai e à cidade.

Para uma compreensão mais aprofundada deste affaire que agitou a sociedade romana é necessário considerar a situação no após guerra dos inícios do século II a.C. e a profunda inquietação dos meios dirigentes durante estes anos. Na própria Antigüidade, Cícero o considerava um exemplo de política de preservação da religião nacional e do mos maiorum frente às influências estrangeiras e ao desregramento. No século passado, na opinião de Mommsen, o cônsul e o Senado salvaram o equilíbrio político-religioso da República face aos excessos "orientais" 
das bacantes (PAILLER, 1982, p. 930). Há neste caso tantos ângulos que ocorre um acúmulo de interpretações sobre os acontecimentos. Encontramos referências a estes fatos em obras que tratam do direito e da constituição romana, da história das mulheres, de movimentos sociais, sem falar, obviamente, da história das religiões.

A repressão aos adeptos do culto de Baco contrasta com a prática romana de tolerância e introdução de novas divindades; durante longo tempo o governo havia conseguido introduzir novos cultos, mas mantendo-os sob controle, excluindo os elementos mais estranhos ao costume religioso romano. Até as divindades dos inimigos eram transferidas a Roma, onde eram objeto do mesmo culto. Sempre foi claro que os romanos combatiam seus inimigos, mas respeitavam os deuses deles. A preocupação fundamental era executar os atos políticos necessários, mas sem ofender as divindades. Foram, portanto, raros os casos de repressão religiosa; mesmo quando isto ocorreu, como em 186, esta preocupação permaneceu: o senatus-consulto que ordenava a perseguição permitia a indivíduos isolados praticar o culto báquico privadamente, caso sentissem uma necessidade pessoal irreprimível. A pietas devida ao deus não podia ser simplesmente ignorada; isto iria contra as bases da mentalidade religiosa romana. O governo não tolerava as associações dionisíacas numerosas, que dessem origem a um movimento organizado fora do controle público; seriam autorizadas reuniões de poucas pessoas, regulamentando-se até o número de homens em relação ao número de mulheres, cuja presença promíscua fora um dos motivos alegados para a intervenção do Senado (CLEMENTE, 1977, p. 374).

A segunda guerra púnica marcou um período de crise gravíssima; o perigo representado pela invasão anibálica na península provocou na sociedade o recurso a novas formas de religiosidade e o afloramento do irracional; o fenômeno da helenização tomou novo impulso, com o envolvimento cada vez mais amplo de Roma nos assuntos da política grega.

Durante a guerra púnica as manifestações religiosas se acentuaram: prodígios, práticas mágicas, e outros eventos se multiplicam nos relatos existentes sobre o período. O governo procurou limitar as manifestações coletivas, tomando medidas para manter a ordem pública, mas foi forçado a concessões à instabilidade do sentimento popular. Em 205 a.C. uma decisão sem precedentes foi tomada pelo governo: uma resposta dos Livros Sibilinos aconselhara a trazer para Roma a representação anicônica da Magna Mater, venerado em Pessinunte. Tratava-se de um culto com manifestação de caráter orgiástico, oficiado por sacerdotes eunucos, sendo a primeira divindade oriental a entrar em Roma. O culto foi expurgado dos aspectos do ritual que eram mais diferentes do costume romano, sendo proibido 
aos cidadãos romanos oficiarem o rito. Em 204 a.C. foi transportada para Roma a pedra negra, símbolo da deusa frígia. O Senado fazia uma concessão ao sentimento religioso mais popular, mas ao mesmo tempo procedia a uma "pasteurização" do culto. Note-se que o templo da Magna Mater foi dedicado em 191 a.C. no Palatino, dentro portanto do pomério, o qual demarcava a área da cidade dentro da qual, entre outras interdições, as divindades estrangeiras normalmente não eram admitidas. A Magna Mater permaneceu, contudo, um caso isolado, resultado da profundidade da crise enfrentada pela cidade num dos momentos mais difíceis da guerra. Novos cultos orientais em Roma, mas dentro de outras condições, somente serão admitidos no século I a C.

Em oposição à tríade Capitolina, existia desde os primeiros anos da República, em 496 a.C., o templo de Ceres, Líbero e Líbera no Aventino, constituindose no centro religioso plebeu; a tríade plebéia era cultuada, portanto, também num local extra-pomério. Líbero ${ }^{5}$ foi depois assimilado a Dioniso, no que se pode considerar uma grecização de um antigo culto agrário. É preciso ressaltar a importância assumida pelos cultos plebeus em Roma e a sua topografia relacionada com o Aventino, bairro tradicionalmente plebeu. Ligado às atividades portuárias, os seus moradores eram constituídos desde negotiatores, homines novi até uma grande maioria de plebeus humildes; sua população caracterizava-se por ser marcadamente heterogênea. Ora, no relato de Tito Lívio, o Aventino se destaca: a liberta Híspala ali residia e o interrogatório a que foi submetida ocorre também ali. Mais importante ainda: é dito que os mistérios noturnos das bacanais aconteciam no bosque sagrado, o lucus Stimulae (Liv. XXXIX 12,4), sendo Stimula uma antiga divindade itálica identificada com Sêmele. Este bosque localizava-se na encosta noroeste da colina, entre o Aventino e o Tibre. Scheid (SCHEID, s/d, p. 490) considera que os ritos báquicos perseguidos constituíam-se em desvios de cultos femininos como os ritos campânicos de Ceres e os velhos ritos de Estímula, os quais, como outros ritos matronais (por exemplo, o da Bona Dea, o de Vênus Verticórdia e Ceres), estavam todos implantados no Aventino, bairro tido como "marginal". A repressão de 186 consistiria, portanto, um esforço de restauração de antigos cultos plebeus do Aventino, desvirtuados nos anos anteriores. A Ânia Pacula e o graeculus da Etrúria não evocam profetas órficos que percorriam as cidades levando uma "mensagem" para iniciados ligados por juramentos secretos (o que podia ser interpretado como coniuratio) introduzindo modificações nos cultos estabelecidos?

Em nossas fontes as figuras centrais de todo o episódio são as mulheres e os jovens. Daí alguns historiadores aventarem explicações de cunho "psicológico"; na sociedade romana estes personagens se encontravam sob o domínio total do 
poder do pater familias e não dispondo de outras formas de protesto, teriam encontrado esta forma de escapar do controle familiar e dos sacerdotes oficiais ligados ao senado. Em outras palavras, uma rebelião contra a supremacia masculina por parte de mulheres, jovens aristocráticos sob tutela, além de libertos e escravos.

A repressão do Estado foi dura: mais de sete mil foram implicados e mais de seis mil foram encarcerados ou condenados à morte, a maioria na Itália do Sul e em Roma. O castigo dos homens implicados revestiu-se de caráter público; ao contrário, a punição das mulheres foi confiada aos seus pais ou entregues àqueles de quem dependiam (Liv. XXXIX 18,6). O castigo delas não seria público, a não ser que ninguém reunisse as condições para se encarregar do suplício. Seria uma forma de sublinhar a incapacidade pública da mulher, manifestando "a reentrada na ordem patriarcal, a "normalização" do grupo das mulheres." 6

A repressão às Bacanais pode ter sido um pretexto para o Senado de Roma aniquilar elementos perigosos para o Estado, pertencentes a grupos religiosos e políticos radicais. Além do aspecto relacionado com a subversão interna, e com a atividade de grupos à margem do poder dentro da sociedade romana, é preciso considerar a relação de Roma com outra áreas itálicas, sobretudo as de dominação recente e culturalmente ligadas ao mundo helênico. Escravos vindos da Itália Central ou refugiados livres durante a guerra constituíram importante fator de difusão do culto a Baco.

Assim as Bacanais podem ter sido encaradas como uma ameaça externa, como uma coniuratio com conotação religiosa por parte de populações recém submetidas, como um protesto desenvolvido particularmente na Campânia. Tito Lívio menciona ainda a Etrúria, também área de submissão recente, de onde o "grego ignóbil exportou o mal para Roma"; de lá eram provenientes os arúspices e as mulheres eram liberadas e poderosas.

Escavações francesas permitiram a descoberta em Bolsena - a Volsinii romana herdeira da capital religiosa etrusca Velzna - de um conjunto subterrâneo com decoração báquica erigido, segundo os dados arqueológicos, por volta do ano 200, e destruído alguns anos mais tarde. A implantação de um santuário de Baco neste local -território etrusco- e neste momento preciso, levou Pailler à conclusão de que era uma confirmação da contaminação etrusca no ponto de partida do "mal báquico" que atingiu Roma, sem que esta confirmação exclua outras origens, principalmente a campânica (PAILLER, 1982, p. 945).

Considerando o contexto social e religioso daquele início do século II a.C., o escândalo seria a expressão de movimentos clandestinos de resistência contra a 
ordem romana, particularmente na aristocracia campânica. Seria parte de uma religiosidade nova, de inspiração neo-pitagórica, que teria penetrado na Etrúria, renovando a religião tradicional e que teria atingido mesmo os meios mais oficiais de Roma?.

Além de acusações de prática de crimes comuns, como assassinatos, indução a testamento, a imagem criada desde a época romana foi a de costumes dissolutos ligada ao termo Bacchanalia. De um sentido inicial associado à idéia de "festejar Baco", desenvolveu-se em seguida outro, "estar em estado de embriaguez ou de exaltação; agitar-se furiosamente ou sem freios". Este sentido pejorativo permaneceu nas línguas modernas. Talvez os ritos simbólicos de morte e ressurreição dos iniciados forneceram material que originou a descrição das orgias. Sociedades secretas femininas, com música, danças à luz de tochas, vinho, nunca foram estranhas a festividades de caráter agrícola e com a busca de contato com a divindade. Talvez os ritos báquicos parecessem às autoridades uma inversão dos valores romanos tradicionais, que incluíam organizações matronais permitidas pelo sistema, direcionando o modelo feminino para o papel de mãe e esposa. Elementos religiosos, incluindo-se o papel das mães iniciadoras como Sêmele, a mãe de Dioniso, e os subterrâneos dos mistérios, descritos como "antros", puderam fornecer material para a imaginação e para as acusações. Na voz de Tito Lívio encontra-se, além disso, o linha da política moralizante de Augusto, preocupado com a restauração do mos maiorum e dos cultos tradicionais.

A análise dos documentos disponíveis sobre as Bacanais em Roma durante a República conduz a uma complexa realidade social e política que deve ser necessariamente considerada para permitir uma melhor compreensão deste fato que transcende ao aspecto unicamente religioso. Em Roma o culto estava na base das relações entre a comunidade humana e o conjunto dos deuses; o aspecto ritual da religião adquiriu uma qualidade autônoma. A teoria romana do Estado era indissociável do núcleo teórico da religião. A religião é cívica e o culto privado só é admitido enquanto não a contrarie.

O senatus-consulto sobre as Bacanais não perdeu a validade. Os seus efeitos foram temporários, pois o próprio Tito Lívio menciona que Tarento em 184 a.C. ainda estava agitada, tendo o pretor Lúcio Postúmio perseguido infatigavelmente o que restara da conjuração das Bacanais (Liv. XXXIX 41) e que em 181 a.C. o pretor Lúcio Durônio ficou encarregado de proceder a investigação sobre as Bacanais, escândalo do qual alguns sintomas haviam reaparecido desde o ano anterior (LIv. XL 19). As autoridades não tentaram eliminar o culto, uma vez que 
Baco era parte do Panteão romano. Tanto no documento constituído pelo decreto do senado quanto no relato de Lívio não se encontra qualquer ataque ao deus, respeitável pela antigüidade e com tanta afinidade espiritual com um povo agrícola. Com o advento do Império, houve um recuo inicial de seu culto sob Augusto, pois o príncipe preferiu associar a sua própria imagem à de Apolo, para marcar a distância em relação ao rival derrotado, Marco Antonio, o novo Dioniso. A luta entre ambos foi em certa medida representada como a de duas naturezas diversas: o príncipe romano apolíneo e o monarca dionisíaco oriental. Ao longo do império a religião báquica voltará a ser associada à figura de certos príncipes, especialmente os Antoninos e os Severos. O deus protetor dos vinhedos servirá também de inspiração para as artes plásticas, além de permanecer ligado à idéia de renascimento espiritual e vida eterna.

\section{Notas}

* Profa. Dra. do PPG História Social da FFLCH/USP.

1 Tornou-se propriedade da família dos Cigala, na província de Catanzaro; no século XVIII passou a pertencer ao imperador Carlos VI, encontrando-se hoje no Kunsthistorisches Museum, em Viena.

2 Corresponde a 7 de outubro de 186 a.C.

3 Pelo menos dezessete, no máximo trinta e um dias; há dúvidas se trinum nundinum é tria nundina ou é a extensão do tempo no qual três nundina caem. (ARCHAIC inscriptions, 1993, p. 258).

4 PAILLER, J.-M. Bacchanalia. La répression de 186 av. J.C. à Rome et en Italie; vestiges, images, tradition. (BEFAR, v. 270). Roma: École Française de Rome,1988. p 251. Apud SCHEID, s/d, p. 491.

5 Líbero é o Dioniso itálico. O seu nome foi relacionado com um dos epítetos habituais de Dioniso, o libertador, ou "aquele que desata". Uma das divindades rústicas latinas muito antiga, nos poetas surge como simplesmente um equivalente de Dioniso. Tinha um paredro, Líbera, freqüentemente associada a Ceres.

6 Pailler, op. cit., p. 592. Apud SCHEID, s/d, p. 491.

7 Cf. GRANET, J. Dionysos contre Rome. Pallas. Revue d'Etudes Antiques. Toulouse, t. 36, 1990. Apud VAN LANGENHOVEN, 1992, p.792-793.

\section{REFERÊNCIAS BibLIOGRÁFICAS}

CALABI-LIMENTANI, I. Epigrafia latina. 3.ed. Milano: Cisalpino-La Goliardica, 1973. 
DE MARTINO, F. Storia della costituzione romana. 2. ed. Napoli: Eugenio Jovene, 1973. v. 2.

LIVY. Translated by E. T. Sage. Cambridge (Mass.); London: Harvard University Press; W. Heinemann, 1983. v. 11 (Books XXXVIII-XXXIX).

MAHÉ, N. Le mythe de Bacchus. Fayard, 1992.

MAZZARINO, S. Il pensiero storico classico. 4 ed. Roma; Bari: Laterza, 1974. v.3.

PAILLER, J.-M. La spirale de l'interprétation: les Bacchanalles. Annales ESC; v. 37, n. 5-6, p. 929-952, sep.-déc.1982.

PRIETO ARCINIEGA, A.; YLL, E. S. El papel de la mujer en las Bacanales romanas. Actas del Coloquio. Paganismo y Cristianismo en el Occidente del Imperio Romano. Memorias de Historia Antigua. V. 5, 1981. Universidad de Oviedo. p. 143-151

SCHEID, J. Estrangeiras indispensáveis. Os papéis religiosos das mulheres em Roma. In: PANTEL, P. S. (Dir.) História das mulheres no Ocidente. Porto; São Paulo: Afrontamento; Ebradil, s/d. v.1. p. 465-509.

TARDITI, G. La questioni dei Baccanali a Roma. La Parola del Passato. Napoli, v. 9, p. 265-287, 1954.

VAN LANGENHOVEN. L'Antiquité Classique. v. 61, 1992.

\section{Agradecimentos}

Agradeço ao Prof. Dr. Eduardo Tuffani, da Universidade Federal Fluminense, a revisão da tradução do Sc. de Bacchanalibus e as sugestões feitas por ele quando discutimos o texto.

CORASSIN, M. L. Bacchanalia dans la République romaine.

RÉSUMÉ: Nous étudions ici une source épigraphique, le sénatus-consulte promulgué à l'époque de la répression des Bacchanales, dans le contexte politico-social; ce document nous renseigne sur les mesures prises en 186 av. J.-C. par le sénat romain contre les manifestations considerées dangereuses à l'ordre public.

MOTS-CLÉS: Bacchanales; Dionysos; Sénat romain; histoire des religions. 